\title{
Wine Consumption Determinants in Albania Using Categorical Regression Model
}

\author{
Ilir Kapaj ${ }^{1}$, Albana Gjoni ${ }^{1}$, Sadik Maloku ${ }^{2} \&$ Ana Mane Kapaj ${ }^{1}$ \\ ${ }^{1}$ Faculty of Economy and Agribusiness, Tirana, Albania \\ ${ }^{2}$ University Ukshim Hoti, Prizren, Kosovo \\ Correspondence: Sadik Maloku, University Ukshim Hoti, Prizren, Kosovo.
}

Received: July 16, 2020

doi:10.5430/rwe.v12n1p204
Accepted: September 10, 2020

Online Published: January 6, 2021

URL: https://doi.org/10.5430/rwe.v12n1p204

\begin{abstract}
The increasing trend of wine consumption in Albania has led the development of the respective subsectors, viticulture and the wine industry. In the order for the domestic wine production industry to be competitive, a detailed understanding of the consumer's buying behavior is a prerequisite. To this end, this study offers an actual perspective of the consumption behavior of wine customers in Tirana region. One of the goals of this paper is to identify and quantify determinants of wine consumption by using a regression model called "Categorical Regression Estimation" for non-numeric response variables. A questionnaire has been designed for this purpose, which is based on the literature but also on the recognition of the customer profile in the country, considering several socio-economic factors. Through 230 face-to-face interviews, the aim is to evaluate the impact on wine consumption of income, age, education, religion, nutrition culture, wine prices, wine origin as well as other socio-demographic factors related to the profile of the consumer. The analysis and interpretation of the results reveal interesting factors that determine the wine consumption. Age, education, income level and price of the wine are the main factors affecting the consumer decision to buy wine. Older people (over 40 years old) represent 1.4 times higher willingness to buy wine relatively to the younger people. Meanwhile, among people with higher income level chances that they will buy wine are 2.15 higher relatively to the people with lower monthly income level. From the results appears that education have positive impact on wine consumption while gender does not represent a significant difference.
\end{abstract}

Keywords: wine consumption, wine, market, regression model, buying determinants

\section{Introduction}

The cultivation of vineyards and the production of wine are activities of a relatively long history in Albania. In three decades, these two sectors have changed significantly which has also changed significantly the wine consumption that has actually led to the development of the respective subsectors, that of viticulture and the wine industry.

Thanks to its geographical position, number of sunny days, fertile soil and indigenous varieties, Albania has the potential to develop a competitive wine industry in the region and beyond. Currently Albanian producers operate in a difficult market, distorted by unfair competition mainly from imported wines. Some producers have invested in vineyards and technology, however there is still no concrete program or plan to promote and support this industry and the product "Made in Albania" leaving the wine market in disarray.

The wine production and viticulture is a well-known and traditional industry in Albania. In the current market, in addition to local dominant wine products, imported drinks are mainly presented in this market, mainly Italian, French, or from the region such as those of Montenegro, Macedonia and Kosovo, etc. Seen in this context, the development of this industry in the country requires special attention and is quite complex especially in terms of grape varieties. The development of the wine production industry aims to complement the consumer taste with local products, and as such this industry takes into account the vineyards, local producers (wineries and factories), packaging providers and local traders. Meanwhile, the importers of these products from Italy, France, but also from the region undoubtedly remain a very important factor in this market.

This product occupies a modest weight in household expenses but which increases from year to year as a result of increasing the economic level and improving the food diet. The competition of imported products is quite fierce as good wine offers the possibility of price liberalization which translates into quality wine but higher price to be paid 
by the consumer. Meeting the standards of production and product hygiene, product certification, increasing food safety, storage and trade according to all norms of the European community are some of the issues that are worrying the Albanian entrepreneur.

According to Skreli and Imami (2019), there has been an increase of grape production in Albania with almost $250 \%$ from 2000 in 2016. This has happened mainly because of the subsidies schemes introduced by Albanian government in late 2000s helped to increase cultivation area and production yield. A quite significant increase has occurred in the wine production in the same years, with 2.5 times (Skreli \& Imami, 2019, p.5).

Skreli and Imami (2019) found that despite increase in production in recent years, wine production in Albania still has good potentials to get better. According to them, the ratio imports/exports is still quite higher in terms of imports. They concluded in their study that there is a potential to replace imports and also to benefit from the increasing tourism sector in Albania. What should be in focus is that quality and efficiency are improved at the level of production and processing of farms / grapes. The value chain of wine has potential to be considered as priority sector considering wine import substitution and constantly growing Agri-tourism market (Skreli \& Imami, 2019 p. 7).

The wine market in Albania is dynamic and has seen a remarkable development over the last few years both from the demand point of view as well as from the supply side. There has been an increase in quality and quantity of the demand side followed by constant efforts of the wine production sector to cope with this demand.

At the national level, the amount of wine consumed in our country in the last 20 years has been marked by unclear fluctuation that can be explained by the oscillations of macroeconomic and political-social indicators. At the regional level, the Albanian consumer stands at the lowest level of wine consumption per capita.

Consumers in Albania usually buy products like wine and rakia from primary producers. They often go to the farmers market or even in the country side to buy. A low-middle income consumer in Albania is more likely to be more oriented towards wine produced in the farm. While a middle -high income consumer is more and more shifting towards mode international labels. Also, during the last years consumers, mainly the high income class, are being more aware on the safety issues for wine.

Based on the study of Zhllima et. al (2012), the place where wine is produced is the most important factor that orient the consumers behavior in the market. Based on different studies, consumers in Albania prefer Albanian wine compared to imported one. And even the region in which wine is produced, within Albania, has a strong influence among consumers behavior. Zhllima et. al (2012) stated that most of the Albanian consumers view the region/area of origin to be either important or very important when they take decision to buy products.

According to Zhllima et. al (2012), local wine is not dominant in Albanian market. Wine coming from EU imports and in particular from Italy predominate in the market They also state that in wine market in Albania there is a potential local wine, and a group of consumers that are willing to pay higher prices for local wine is identified. Consumers prefer Albanian wine coming from particular regions, like Permet, Vlore and Lezha. In those regions, there is also a tradition of grape production and processing. The majority of respondent's included in their study, are willing to pay a high prices for the preferred origin (Zhllima et al., 2012).

In this context another study by Vukatana, Sevrani, \& Hoxha (2016) investigates the alternatives of wine traceability as an critical issue that has gained importance internationally. Food quality control schemes are mandatory for EU member states and USA. Aiming to join the EU Albania has transformed most of the EU food regulation into laws. Regarding the vine sector, the obligation of wine producers to keep traceability data is part of the legislation. Furthermore, with regards to the consumers, the traceability system gives them transparency - the ability to trust that they know what they are drinking. Companies that build this kind of relationship with their customer, will most likely have a rapid gain in the market share (Vukatana et al., 2016).

Introducing quality schemes in wine production, such as Geographical Indications (GI) is found to represents a potential by Zhllima et. al (2012). The autochthon grape varieties grown to specific region in Albania, for centuries (eg. Serina in Korca, Vlosh in Vlora, Pules in Berat, Kallmet in Lezha), indicate a relation between a specific cultivar and a specific geo- graphical area and represents a potential for developing wine quality scheme, including GI but not limited to (Zhllima et al., 2012).

Per capita consumption in neighboring countries is much higher than in Albania. Apart from the continual increase of the domestic wine production by industry and by artisan way of production, wine import has experienced a rapid increase in recent years.

Based on the above facts, the analyses that follow are considered of high importance and critical in dissecting the 
factors that determine wine consumption and its trend. This paper is focused on wine market research with the main aim of identifying the factors that determine consumer behavior and decision making in relation to wine consumption in the region of Tirana.

\section{Literature Review}

There exist different studies from various researchers pertaining to different countries which assess and evaluate factors that affect wine consumption.

Camillo (2012), identifies some factors that affect wine consumption such as: consumer education, other activities related to wine (subsidiary products), distribution channels, quality, price, the origin and the income level.

Another study by Georgiana, Roxana, Silviu, \& Cosmin (2014) carried out in Rumania, reveals that price is very important in consumer's buying decision making in addition to other variables like quality.

Stanciu (2015), interviewed 1000 consumers in Moldavia. As final result, wine consumption is dependent on quality, price and income level. In this study it has to be emphasized that gender and age structure of the population does not have a significant effect in wine consumption.

In empirically testing determinants of wine consumption among American consumers, responses from 122 surveys disclosed a significant positive relationship between knowledge and consumption of wine. Although age and race appear to influence consumption of wine, knowledge remains the most important determinant in wine consumption (Hussain, Cholette, \& Castaldi, 2007).

Hertzberg \& Malorgio (2008) conducted a choice experiment on 444 wine buyers in North-Eastern Italy, simulating the choice of a wine for ordinary consumption, at a supermarket. They discovered that the presence of DOC or IGT designations of origin, a known brand and the indication of the grapevine variety on the label increase the choice probability and are all associated with a positive WTP. The price has a smaller influence than other attributes and its relationship with utility is quadratic. The private label only slightly affects the consumer choices, with a negative or positive effect depending on the wine initial price (Hertzberg \& Malorgio, 2008).

Schamel in 2017explored the key components of consumer demand for the development of a successful wine and culinary tourism segment in South Tyrol. By utilizing the 4E-Model of experiential consumption by Pine \& Gilmore and propose that the four realms of an experience (i.e., entertainment, education, escapist, and aesthetic) relate to the principal components of consumer preferences. The author used an exploratory factor analysis, and identified the principal components of consumer demand preferences. The most preferred demand feature of a culinary wine experience relates to informative entertainment. The second feature relates to social-cultural activities that are educating. The third are escapist wine and food-specific activities and the fourth relates to the aesthetics of accommodation traits and style in the culinary and wine domain (Schamel, 2017).

Another study by Mauracher, Procidano, \& Sacchi in 2014 explore the demand of wine tourists at different stage of their experience. In particular, their research is focused on identifying which are the preferences and needs of wine tourists that decide to visit Prosecco production territories, taste and buy local products. In general terms, the results of the logit model used by the authors show that having more than 60 years, having planned another wine tourism experience, consuming often Prosecco and being a foreign tourist are the determinants of visiting the Prosecco District. They argue that the findings will increase from one hand the level of knowledge of tourists' preferences and, from the other, they will help in matching tourists' expectations and needs. Having a broad and complete picture of wine tourists' motivating factors, characteristic and satisfaction, indeed, will allow firms to position adequately into the market (Mauracher et al., 2014).

Wang in 2011investigated Chinese consumers' preferences for wine and food products. A logistic regression model is applied to analyze how purchasing habits and behavior are related to socio-demographics, and to predict the probability of potential wine consumption occurrence and frequency in a short-term. Findings include that Income and education both have a marginally significant positive effect on consumption of wine (Wang, 2011).

The food industry in response to rising level of concern regarding the relationship between diet and health, has developed so-called "functional foods". In this context Barreiro-Hurlé, Colombo, \& Cantos-Villar (2008) carried out an exploratory valuation exercise regarding the potential market for functional wine, a wine produced from grapes, in which the resveratrol content has been enhanced. Results of this study suggest that the functional attribute positively and significantly affects the probability of selecting a red wine and that the willingness to pay for this attribute is as important as for ageing in wine (Barreiro-Hurlé et al., 2008).

In reference to food products and factors that influence consumers behavior, Kapaj in 2013, have used different 
socio-economic factors to analyze their significance in the final consumer behavior. Among these factors they have used specifically Age, Education, Income level and Price of the product. These are the mostly used factors in most of the consumers' behavior studies. (A. Kapaj, Deci, Kapaj, \& Mece, 2013) (I. Kapaj \& Kapaj, 2013)

A study from Srivastava, Mclaren, Wohlgenant \& Zhao (2015) aim assessing estimates of price elasticity of demand for 12 disaggregated alcoholic beverages in Australia (red bottled wine, white bottled wine, sparkling wine and cask wine). Results indicate elastic own-price elasticity for virtually all commodities. Any proposed tax increase to cask wine may also result in consumers shifting demand to more undesirable beverages (other strong alcoholic drinks) (Srivastava et al., 2015).

The empirical findings among Canadians consumers reveal that consumers' response to foreign-produced wines differs from that for wine produced locally. It is evident that the expenditure elasticity for British Columbia, European and Rest-of-the-World white wines are larger than those for red wines (Carew, Florkowski, \& He, 2004).

The premium wine segment has expanded significantly to the detriment of basic wines. Nevertheless, in traditional wine producing and consuming countries, inexpensive wines still account for a large market share, both in volume and value (similar to the case of Albania) (Cembalo, Caracciolo, \& Pomarici, 2014). The authors in this study state that the marketing strategies for such wines are changing in an attempt to tap this increasingly crowded market segment. QUAIDS Censored Method was used in a panel of 6,773 Italian households to see at what extend, substitution occurs in the home consumption of basic wines, which is the key medium for the distribution of cheap wines in Italy. While price is an essential element in supply policies, findings also indicate the significance of packaging as a substitute to glass, for example carton. (Cembalo et al., 2014).

According to Barber, Almanza, \& Donovan (2006), has determined in their study that label design and bottle closures were important to respondents. Also they have concluded that self-confidence was a significant factor for age and gender, with females and respondents between 31 and 40 years of age more concerned about making a wine-buying decision (Barber et al., 2006).

Although there are quite a large number of studies carried out by different authors in different countries aiming at determining factors that influence consumer decision for food product in general and for wine in particular, there is a lack of such studies in Albania. Determining factors that influence wine consumption in Albania will help wine producers marketing decision to target more effectively wine consumers based on Age, Education, Gender and Income level.

\section{Research Methodology}

The objective of this study/paper is to identify and quantify determinants of wine consumption by using a regression model called "Categorical Regression Estimation" for non-numeric response variables. A questionnaire has been designed for this purpose, which is not only based on the literature but also on the recognition of the customer profile in the country, taking into account several socio-economic factors. Through structured questionnaire and face-to-face interviews, we gathered data from consumers. The total number of respondents was 230, roughly half of them females and half males. They were randomly chosen by trained interviewers, usually in the supermarkets of Tirana. The samples chosen, higher than 200, assures a good representation of the wine consumer's population in Tirana. The interviewers were aware to choose the interviewees aged over 25 . This criterion is quite necessary for the sample selection as this group of people is potentially wine consumers. By analyzing the data using SPSS software, we aim to evaluate the effect of income level, age, education, religion, food diet, wine price, wine origin and other socio-demographic factors closely related to consumer profile.

\section{Results}

As mentioned above the main goal of this study is to assess the effect of the factors that determine wine consumption in the Tirana region. In the beginning we thought, as literature suggests, to investigate the determinants of wine consumption like income, age, education, religion, nutrition culture, wine prices and wine origin.

Wine consumption is measured as binary variable.

Do you consume wine? A12 (1=Yes; 2=No)

Dependent variables:

- $\quad$ A5- Education (1. Elementary school; 2. High school; 3. University; 4. Professional School

- A8- Religion (1. Muslim; 2. Cristian)

- $\quad$ A10 - Age (1. 18-30; 2. 31-40; 3. 41-50; 4. 51-60; 5. >60) 
- A16.1- Wine origin domestic (1. Yes; 0. No)

- A16.2 - Wine origin domestic (1. Yes; 0. No)

- A19.1- Is price important factor affecting your buying behavior (1. Yes; 0. No)

- A20 - Income level (1. Up to 50.000 ALL; 2. 51.000 - 100.000 ALL; 3. 100.000-150.000 ALL; 4. More than 150.000 ALL.

Dependent variable (A12) is categorical binary variable. Again, all other independent variables are categorical. Literature suggests that before running in SPPS the binary logistic regression we must run a Spearman's rho correlation matrix. The reason behind this is to determine the variables which are significantly correlated and are responsible for much of variation in dependent variable. Correlation matrix in Table 3 below reveals that only two are significantly correlated with dependent and that is A20 (Income level) and A5 (Education level). A19.1 (price level) with close to $95 \%$ confidence level can be included in the binary logistic and using the same judgment A10 (Age) with confidence level $92.7 \%$.

Table 1. Correlation coefficients

\section{Correlations matrix}

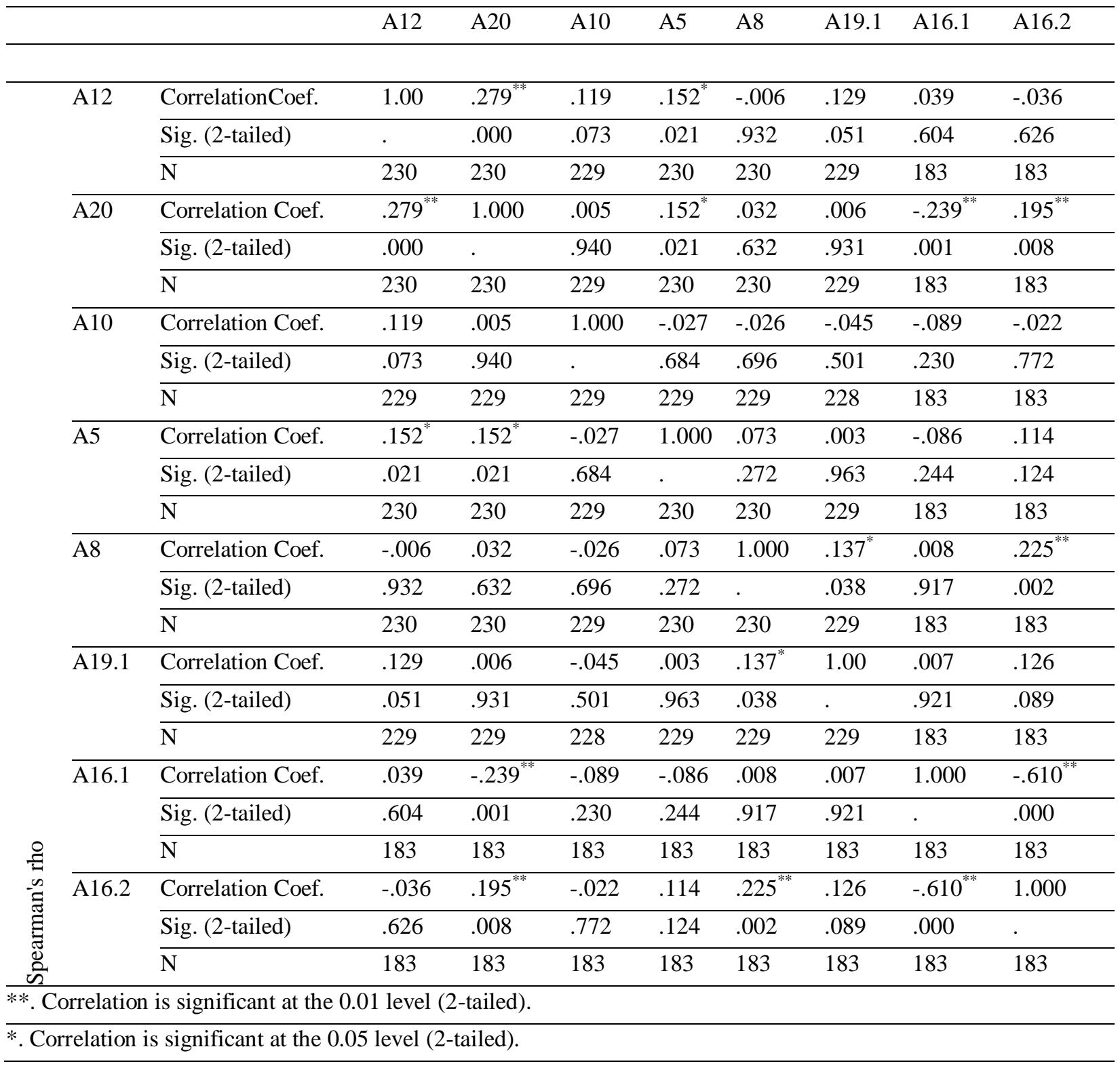


Table 2. Binary Logistic Regression (1: Method = Enter)

\section{Omnibus Tests of Model Coefficients}

\begin{tabular}{lllll}
\hline & Chi-square & df & Sig. \\
\hline \multirow{2}{*}{ Step 1 } & Step & 27.383 & 4 & .000 \\
\cline { 2 - 6 } & Block & 27.383 & 4 & .000 \\
\cline { 2 - 6 } & Model & 27.383 & 4 & .000 \\
\hline
\end{tabular}

\section{Model Summary}

\begin{tabular}{llcc}
\hline Step & -2 Log likelihood & Cox \& Snell R Square & Nagelkerke R Square \\
\hline 1 & $207.299^{\mathrm{a}}$ & .113 & .176
\end{tabular}

a. Estimation terminated at iteration number 6 because parameter estimates changed by less than .001 .

\section{Hosmer and Lemeshow Test}

\begin{tabular}{llll}
\hline Step & Chi-square & df & Sig. \\
\hline 1 & 26.156 & 8 & .001 \\
\hline
\end{tabular}

\begin{tabular}{|c|c|c|c|c|c|c|c|}
\hline \multicolumn{8}{|c|}{ Variables in the Equation } \\
\hline & & $\mathrm{B}$ & S.E. & Wald & df & Sig. & $\operatorname{Exp}(B)$ \\
\hline \multirow{5}{*}{ Step $1^{\mathrm{a}}$} & A10 & .329 & .167 & 3.860 & 1 & .049 & 1.389 \\
\hline & $\overline{\mathrm{A} 5}$ & .539 & .307 & 3.079 & 1 & .079 & 1.714 \\
\hline & A19.1 & 1.879 & 1.052 & 3.191 & 1 & .074 & 6.546 \\
\hline & $\overline{\mathrm{A} 20}$ & .768 & .216 & 12.635 & 1 & .000 & 2.155 \\
\hline & $\overline{\text { Constant }}$ & -2.585 & 1.035 & 6.232 & 1 & .013 & .075 \\
\hline
\end{tabular}

a. Variable(s) entered on step 1: A10, A5, A19.1, A20.

The binary logistic model reveals that explanatory variables show a greater variation in the dependent variable (Omnibus test is significant). This means that Age, Education, Income level and Price of the wine are the main factors affecting the consumer decision to buy wine.

From the variables in the equation table, it appears that A10 (Age) and A20 (Income level) have a significant effect on the dependent (decision to buy wine). So, when we go from one to the other category in "Age" Variable (from younger to older people) the chance to buy wine increases by close to 1.4 times with respect to the preceding category.

Meanwhile, when we go from the lower to higher categories in the Income level variable, the chances to consume wine increases by 2.15 times more than the preceding category. Education and wine price have an effect on the decision to buy wine although the effect is not that significant. People who don't buy wine, state that price is the main factor whereas when going from the lower echelons of the society to the higher ones, taking into account their level of education too, the prospects to purchase wine increases by 1.7 times in correlation to the preceding category.

\section{Discussion and Conclusion}

Our aim in this paper is the identification and quantification of determinants of wine consumption by using a regression model called "Categorical Regression Estimation" for the response variables that are non-numeric.

Inner wine demand in Albania, in late 2000s, gave a boost to increased cultivation and production. This has happened mostly because of the changes in consumers' lifestyle. Another factor that has influenced this increase are the subsidies schemes from Albanian government. But still if we compare the Albanian wine production is low in comparison with region countries. 
The wine industry in Albania is diverse, dominated by small wineries. Shortage of supply with required grape quantity, prevented companies in winemaking sector to grow. Quality wine brands are still underdeveloped - local producers of high-quality wine somehow succeed to sell the product, but imports of quality wine are also increased, which indicates that domestic wine supply fails to meet the needs of the domestic market in terms of quantity and quality (Skreli \& Imami, 2019). According to Skreli and Imami (2019), Albanian consumers are shifting to wine consumption instead of rakia (traditional drink produced mainly from grape) consumption - as their income level increases leading to different consumption patterns.

The wine consumption decisions among citizens in the Tirana region are affected significantly by age and income level. Other factors like education and price have a significant role in consumer buying decision.

We found the same conclusion in the study of wine buying decision among American consumers (Hussain et al., 2007). According to this study, age and knowledge (here associated with education) affect significantly the buying decisions alongside with race.

According to Salai, Gasovic, \& Celic, wine consumers' behavior, in Vojvodina, is strongly influenced by the environment and their personal factors. In more detailed explanation these factors are geographic, demographic, economic, sociological, social, cultural, political and legal determinants (Salai, Gasovic, \& Celic, 2013).

According on the reported choice of 953 Italian wine buyers, the income and purchasing patterns in wine shops and the habit of drinking between meals have a big effect on the attitude to purchase Sicilian wines. Based on a study carried out in Italy it has been evaluated that these factors do influence the consumers' behavior in the market. (Caracciolo, Di Vita, Lanfranchi, \& D’Amico, 2015).

The overall aim, of a study conducted by Bruwer, Saliba, \& Miller, (2011) among Australian regions, is to gain some insights into the product style preferences of consumers and what this means in practical terms to wine product marketing.

They found that specific differences exist in the wine consumption behavior and sensory preferences of males and females and between generational cohorts, specifically Millennial and older consumers. Females drink less wine than males, spend less thereon but tend to "compensate" for this by buying higher priced wine per bottle, which could represent a risk reduction strategy (Bruwer et al., 2011).

The wine production sector in Albania has to cope with the consumer demand characteristics while striving for growth and expansion. Although, wineries try to serve all consumer segments they must consider that people with high income level and over 40 years old are more willing to buy wine despite the price level.

Viticulture and the wine industry development have shown an increasing trend in Albania. In the last decades, these two sectors have changed significantly. This change has led to the wine consumption changing trends as well. At the national level, the amount of wine consumed in our country in the last 20 years has been marked by unclear fluctuation that can be explained by the oscillations of macroeconomic and political-social indicators. The wine market in Albania is dynamic and has seen a remarkable development over the last years both from the demand point of view as well as from the supply side. The wine industry in Albania varies, from newly established small wineries to the largest ones privatized from former state-owned wineries.

The factors that are thought to mostly affect and determine the wine consumption in Tirana region are income, age, education, religion, nutrition culture, wine prices and wine origin.

According to the results of the study, Age, Education, Income level and Price of wine are the main factors affecting the consumer buying decision. Education and Price have an effect on the decision to buy wine although the effect is not that significant. People who don't buy wine, state that price is the main factor whereas when going from the lower echelons of the society to the higher ones, taking into account their level of education too. Also, according to the results of the study, the wine consumption decisions among citizens in Tirana region is significantly affected by age and income level.

The effect of wine consumption determinant in Tirana region might not be the same in other regions of Albania. South region of Albania, famous producing and consuming Rakia before 1990, is dominated by the legacy of consuming Rakia. Therefore, the wine market determinants in this region and their weight in consumer decision might be different compared to Tirana region. The same applies to north region of Albania, where wine market is underdeveloped as a result of low-income level and traditional consumption pattern related to alcoholic drinks. The methodology carried out in our study is worth to be applied in future research in other regions of Albania. The findings of this study have to be seen in light of some limitations. The first is the small sample size and specific study 
area. Study is focused in urban Tirana and the sample size could have been higher. The second limitation concerns the lack of availability of data related to wine production.

As a conclusion, among the socio-economic factors that we investigated to determine the wine consumption in Tirana region, age and income level are the ones that significantly affect the consumers' behavior to buy wine.

\section{References}

Barber, N., Almanza, B. A., \& Donovan, J. R. (2006). Motivational factors of gender, income and age on selecting a bottle of wine. International Journal of Wine Marketing, 18(3). https://doi.org/10.1108/09547540610704774

Barreiro-Hurlé, J., Colombo, S., \& Cantos-Villar, E. (2008). Is there a market for functional wines? Consumer preferences and willingness to pay for resveratrol-enriched red wine. Food Quality and Preference. https://doi.org/10.1016/j.foodqual.2007.11.004

Bruwer, J., Saliba, A., \& Miller, B. (2011). Consumer behaviour and sensory preference differences: implications for wine product marketing. Journal of Consumer Marketing, 28(1), 5-18. https://doi.org/10.1108/07363761111101903

Camillo, A. A. (2012). A strategic investigation of the determinants of wine consumption in China. International Journal of Wine Business Research, 24(1). https://doi.org/10.1108/17511061211213792

Caracciolo, F., Di Vita, G., Lanfranchi, M., \& D’Amico, M. (2015). Determinants of sicilian wine consumption: Evidence from a binary response model. American Journal of Applied Sciences. https://doi.org/10.3844/ajassp.2015.794.801

Carew, R., Florkowski, W. J., \& He, S. (2004). Demand for domestic and imported table wine in British Columbia: A source-differentiated almost ideal demand system approach. Canadian Journal of Agricultural Economics. https://doi.org/10.1111/j.1744-7976.2004.tb00101.x

Cembalo, L., Caracciolo, F., \& Pomarici, E. (2014). Drinking cheaply: The demand for basic wine in Italy. Australian Journal of Agricultural and Resource Economics. https://doi.org/10.1111/1467-8489.12059

Clements, K. W., \& Selvanathan, S. (1991). The economic determinants of alcohol consumption. Australian Journal of Agricultural Economics. https://doi.org/10.1111/j.1467-8489.1991.tb00506.x

Georgiana, L. R., Roxana, S., Silviu, B., \& Cosmin, P. (2014). Romanian wine market - An European approach. In Vision 2020: Sustainable Growth, Economic Development, and Global Competitiveness - Proceedings of the 23rd International Business Information Management Association Conference, IBIMA 2014.

Hertzberg, A., \& Malorgio, G. (2008). Wine demand in Italy: An analysis of consumer preferences. New Medit.

Hussain, M., Cholette, S., \& Castaldi, R. (2007). Determinants of wine consumption of US consumers: An econometric analysis. International Journal of Wine Business Research, 19(1), 49-62. https://doi.org/10.1108/17511060710740343

Kapaj, A., Deci, E., Kapaj, I., \& Mece, M. (2013). Consumers behavior towards milk products in urban Albania. Journal of Food, Agriculture and Environment.

Kapaj, I., \& Kapaj, A. M. (2013). Household consumption of dairy products - An analysis of consumer behavior in Albania. Mediterranean Journal of Social Sciences, 4(9), 104-108. https://doi.org/10.5901/mjss.2013.v4n9p104

Lanfranchi, M., Giannetto, C., \& De Pascale, A. (2014). Analysis and models for the reduction of food waste in organized large-scale retail distribution in eastern Sicily. American Journal of Applied Sciences, 11(10), 1860-1874. https://doi.org/10.3844/ajassp.2014.1860.1874

Mauracher, C., Procidano, I., \& Sacchi, G. (2014). Customer satisfaction for wine tourism innovation: Novel patterns for tourism integration in the Veneto Region. Economia Agro-Alimentare. https://doi.org/10.3280/ECAG2014-001008

Noev, N. (2005). Wine quality and regional reputation: Hedonic analysis of the Bulgarian wine market. Eastern European Economics. https://doi.org/10.2753/EEE0012-8755430601

Noev, N. (2007). Land, wine and trade: The transition of the Romanian wine sector. Eastern European Economics.

Salai, S., Gasovic, M., \& Celic, M. (2013). Marketing research into wine consumption determinants in Vojvodina. Marketing. https://doi.org/10.5937/markt1302103s

Schamel, G. H. (2017). Wine and culinary tourism: Preferences of experiential consumers. BIO Web of Conferences. 
https://doi.org/10.1051/bioconf/20170903021

Srivastava, P., Mclaren, K. R., Wohlgenant, M., \& Zhao, X. (2015). Disaggregated econometric estimation of consumer demand response by alcoholic beverage types. Australian Journal of Agricultural and Resource Economics. https://doi.org/10.1111/1467-8489.12095

Stanciu, S. (2015). The Romanian Retail Food Market - Survival or Success for Domestic Companies. Procedia Economics and Finance, 23(2015), 1584-1589. https://doi.org/10.1016/s2212-5671(15)00505-5

Vukatana, K., Sevrani, K., \& Hoxha, E. (2016). Wine Traceability: A Data Model and Prototype in Albanian Context. Foods, 5(1), 11. https://doi.org/10.3390/foods5010011

Wang, H. (2011). Preferences for wine and food consumption in China. ProQuest Dissertations and Theses.

Zhllima, E., Chan-Halbrendt, C., Zhang, Q., Imami, D., Long, R., Leonetti, L., \& Canavari, M. (2012). Latent class analysis of consumer preferences for wine in Tirana, Albania. Journal of International Food and Agribusiness Marketing, 24(4), 321-338. https://doi.org/10.1080/08974438.2012.716728

\section{Copyrights}

Copyright for this article is retained by the author(s), with first publication rights granted to the journal.

This is an open-access article distributed under the terms and conditions of the Creative Commons Attribution license (http://creativecommons.org/licenses/by/4.0/). 